\title{
Up-Regulation of MiR-452 Inhibits Metastasis of Non-Small Cell Lung Cancer by Regulating BMI1
}

\author{
Zhicheng He $\mathrm{H}^{\mathrm{a}}$ Yang Xia ${ }^{\mathrm{a}}$ Chunfeng Pan ${ }^{\mathrm{a}}$ Teng Ma ${ }^{\mathrm{a}}$ Bin Liu ${ }^{\mathrm{a}}$ Juejin Wang \\ Liang Chen ${ }^{\text {a }}$ Yijiang Chen ${ }^{\text {a }}$ \\ aDepartment of Thoracic Surgery, The First Affiliated Hospital of Nanjing Medical University, Nanjing, \\ Jiangsu, bDepartment of Physiology, Nanjing Medical University, Nanjing, Jiangsu, P.R. China
}

\section{Key Words}

MiR-452 • BMI1 • Invasion • Non-small cell lung cancer

\begin{abstract}
Background/Aims: MicroRNAs (miRNAs) have been regarded as a new class of regulators in cellular processes in non-small cell lung cancer (NSCLC). However, the relationship between miR-452 and the development of NSCLC remains unclear. Methods: qRT-PCR was used to detect the expression of miR-452 and its target gene in NSCLC samples $(n=60)$. The transwell assay was used to test the cell invasion capability. The regulation mechanism was confirmed by luciferase reporter assay and western blot assay. Results: In the current study, a relatively lower miR-452 and higher BMI1 expression levels were confirmed to be associated with advanced tumor stage and more extent of lymph nodes metastasis. In vitro, down-regulated miR-452 could enhance cell invasion capability. Furthermore, miR-452 modulated BMI1 expression by binding to its 3'-UTR. The enhancement of cell invasion capability induced by down-regulated miR-452 was eliminated by repression of BMI1. Conclusions: Our results suggest that miR-452 plays a vital role in development of NSCLC, and this miR-452-BMI1 pathway might generate a novel insight into the treatment of NSCLC.
\end{abstract}

Copyright $\odot 2015$ S. Karger AG, Basel

\section{Introduction}

Lung cancer remains one of the most common malignancies and there were an estimated 1.8 million new lung cancer cases occurred in 2012 worldwide [1]. In China, lung cancer is

Z. He and Y. Xia contributed equally to the manuscript.

Yijiang Chen Department of Thoracic Surgery, The First Affiliated Hospital of Nanjing Medical University, Nanjing, Jiangsu 210029, (P.R. China)

Tel. +86 25 83620988, Fax +86 25 83620988, E-Mail YJChen@NJMU.edu.cn 
the leading cause of cancer death for both men and women [2]. Based on the pathological classification, non-small cell lung cancer (NSCLC), according for $85 \%$ of all lung cancers, is primarily divided into squamous cell carcinoma and adenocarcinoma [3]. Invasion and metastasis are characterized by the capability of cancer cells invading to adjacent area, extravagating into lymphatic and blood vessels and colonizing into a distance environment [4]. Therefore, investigation of the mechanism of the capability of invasion and metastasis of cancer cells would aid us understanding the development of NSCLC.

MicroRNAs (miRNAs) are an abundant class of small non-coding RNAs, roughly 19 22 nucleotides in their mature form. miRNAs mediate a variety of coding genes in post-transcriptional level via binding to the 3'-untranslated region of mRNA, leading to transcriptional repression or message RNA (mRNA) degradation [5]. Recently, miR-452 was reported to contribute to the development of a variety of malignancies such us glioma, prostate and breast cancers, as well as esophageal cancer [6-9]. To date, no data available has documented miR-452 expression in NSCLC.

B-cell-specific Moloney murine leukemia virus integration site 1 (BMI1) modulates epigenetic transcriptional silence and is frequently highly expressed in human malignancies including lung, colorectal, prostate cancers [10-12]. Furthermore, it has also been confirmed that BMI1 functions as oncogene via activation of multiple pathways, which are likely to play vital roles in the prevention of senescence, apoptosis and differenation as well as promotion of proliferation [13].

There has been no document specifically focusing on the relationship of miR-452 and gene BMI1 in NSCLC. The current study mainly investigated the expression of miR-452 in human NSCLC tissues and cells and intended to uncover its underlying mechanism involved in the invasion and metastasis of NSCLC by targeting gene BMI1.

\section{Material and Methods}

Clinical samples

NSCLC tumor tissues and corresponding adjacent tissues were collected from 60 patients who had undergone surgery at the First Affiliated Hospital of Nanjing Medical University from February 2008 to June 2010. We immediately snap-froze all tissues in liquid nitrogen and then stored at $-80^{\circ}$ until RNA extraction. The Ethical Committee of the First Affiliated Hospital of Nanjing Medical University Approved this study. Patients' written informed consents were waived because of its retrospective nature.

Cells and basic experimental procedures

There were four lung cancer cell lines (A549, SPCA1, H358, and H1299) and normal lung cell (16HBE) available for analyses. All cell lines were purchased from Institute of Biochemistry and Cell Biology of Chinese Academy of Science (Shanghai, China). Cells were maintained in RPMI-1640 medium (Gibco, USA) supplemented with 10\% fetal bovine serum (Invitrogen, Carlsbad, CA) and penicillin (100U/ml.). All cells were routinely incubated in chambers at $37^{\circ} \mathrm{C}$ supplied with $5 \%$ carbon dioxide.

Isolation of total RNA and quantitative real-time PCR( $q R T-P C R)$

RNAs were extracted from all the tumor and corresponding adjacent tissues by using TRIzol (Invitrogen, USA) and all the RNAs were reversely transcribed into cDNA using reverse transcriptase kit (TAKARA, Tokyo, Japan). The relative expression levels of miR-452 were quantified using TaqMan microRNA Assays. Quantitative miRNA expression data were normalized to internal "housekeeping" small nuclear RNA U6. Similarly, expression levels of BMI1 mRNAs were assessed by SYBR green qRT-PCR. GAPDH was used for normalization. ABI 7900 fast Real-time PCR system (ABI, CA, USA) were used to perform qRT-PCR. The specific primers are listed as follows: miR-452 reverse transcription primer: GTC GTA TCC AGT GCA GGG TCC GAG GTA TTC GCA CTG GAT ACG ACT CAGTT; miR-452 forward: GCG CAA CTG TTT GCA GAG, miR452 reverse: GTG CAG GGT CCG AGGT; U6 forward: CTC GCT TCG GCA GCACA, U6 reverse: AAC GCT TCA CGA ATT TGCGT.

\section{KARGER}




\section{Cellular Physiology Cell Physiol Biochem 2015;37:387-398

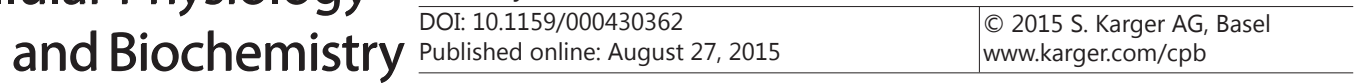

He et al.: Up-Regulation of miR-452 Inhibits Metastasis of NSCLC

Transient transfection

We purchased the following four reagents from GenPharma (Shanghai, China): Oligonucleotides NC (miR-control), miR-452 mimics (has-miR-452 mimics), inhibitor NC (anti-miR-control), miR-452 inhibitor (has-anti-miR-452). The cells were seeded into 6-well plates and transfected with 50nM siRNA/BMI1 (siRNA/BMI1-243: 5'-CCGUCUUAAUUUUCCAUUG-3'; and siRNA/control (GenePharma, Shanghai, China) using Lipofectamine 2000 (Invitrogen, USA) according to the manufacturer's instructions. Cells were transfected with oligonucleotides by using Lipofectamine 2000 Reagent with the final concentration of 100nM (Invitrogen, Carlsbad, CA, USA). Finally, qRT-PCR was performed to test the transfection efficiency of all groups.

\section{Transwell invasion assay}

Transwell assays were conducted with invasion chamber (Millipore, Eschborn, Germany) with 8- $\mu$ m pore size and BioCoat Matrige (BD Biosciences, San Jose, CA) under the instructions of manufacturer. All cell lines $\left(5 \times 10^{4}\right)$ were incubated at $37^{\circ} \mathrm{C}$ for 48 hours, then crystal violet was used to stain the cells. The extents of invasion were assessed by counting three fields per membrane and the average of three independent fields represented the final result. We used NIS Elements image analysis software (Nikon, Tokyo, Japan) to cover above evaluations.

\section{Apoptosis assay}

We detected the apoptosis of cultured cells 24 hours after transfection using annexin V-APC labeled Apoptosis Detection Kit under the instructions of manufacturer (Abcam).

\section{Cell-proliferation assay}

Cells were plated into 96-well plates at a density of $6 \times 10^{3}$ cells per well. Viability of all cells was evaluated by cell-counting Kit-8 Assay (Beyotime, Institute of Biotechnology, Shanghai, China). The absorbance of each well was assessed by using spectrophotometer (Thermo) at $450 \mathrm{~nm}$ (A450). Each experiment was performed in triplicate.

\section{Western blot}

PBS and lysed in RIPA lysis buffer supplemented with protease inhibitor cocktail (Roche, Mannheim, Germany) were used to wash cells. Proteins were extracted from cultured cells, and concentrations were determined using the BCA Protein Assay Kit (Beyotime, Shanghai, China). Proteins were firstly resolved by $8 \%$ to $12 \%$ SDS-PAGE (sodium dodecyl sulfate-polyacrylamide gel electrophoresis) and electrophoretically transferred to polyvinylidene difluoride membranes (Millipore). Secondly, these membranes were blocked in $4 \%(\mathrm{w} / \mathrm{v})$ nonfat milk for $1 \mathrm{~h}$ at room temperature. Finally, they were immunostained with the appropriate primary antibodies (anti-BMI1, 1:1000, Abcam, Cambridge, United Kingdom) at $4^{\circ}$ overnight. The results were detected using a chemiluminescent detection system (Pierce, IL) and exposed in Molecular Imager ChemiDoc XRS system (Bio-Rad, Hercules, CA).

\section{Plasmid construction and cell transfection}

3'-UTR sequence of BMI1 predicted to interact with miR-452 was inserted into KpnI and SacI sites of pGL3 promoter vector (Genscript, Nanjing, China). To correct for transfection efficiency, a mutant sequence of 3'-UTR in BMI1 was also transfected into the luciferase reporter vector in parallel. They were named as pGL3-BMI1 and pGLs-BMI1-mut, respectively. The cells were seeded onto 6-well plates and co-transfected with $100 \mathrm{ng}$ of pGL3-BMI1 (or pGL3-BMI1-mut) and miR-452 mimics (50 nM) by using Lipofectamine 2000 (Invitrogen Corp, CA, USA). BMI1 gene (Genscript, Piscataway, NJ) was restrictively digested using Mlu I and subcloned pLV-GFP plasmid (Provided by Dr. Beicheng Sun, Nanjing Medical University, China). Recombinant lentivirus was obtained from 293T cells using calcium phosphate precipitation and cells were transfected with lentivirus using polybrene $(8 \mu \mathrm{l} / \mathrm{ml})$.

miR-452 luciferase reporter assay

After cell lines were transfected 48 hours, the luciferase reporter assay were detected in Victor 1420 Multilabel Counter (Wallac, Finland) using Luciferase Assay system under instructions of the manufacturer(promega, USA). 


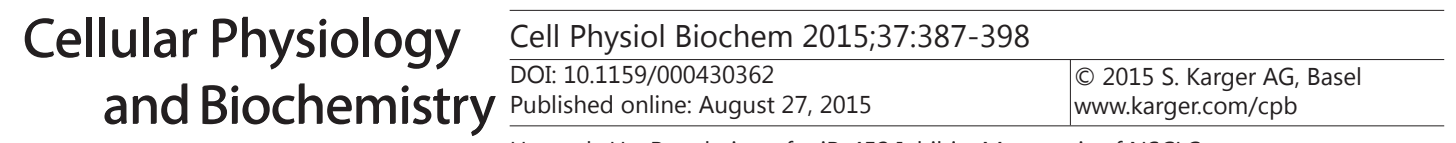

He et al.: Up-Regulation of miR-452 Inhibits Metastasis of NSCLC

Bioinformatics analysis

We used to the bioinformatics method to predict the potential targeting genes of miR-452. According to the results predicted in TargetScan (http://www.targetscan.org/), miRWalk (http://www.umm. uni-heidelberg.de/apps/zmf/mirwalk/), and microRNA.org (http://www.microrna.org/microrna/ getMirnaForm.do), BMI1 was the candidate gene and 3'-UTR of BMI1 binds to miR-452 with a high score.

\section{Statistical methods}

The expressions of miR-452 and U6 were estimated using the method of $2-\Delta \mathrm{Ct}$ in this study. The chi-square test was used to test the significant differences in observed variables presented in Stata 11.2 and GraphPad Prism 5.01 (GraphPad Software, Inc., La Jolla, CA) software. In all these analyses, statistical significance was obtained when $\mathrm{p}$ value was less than 0.05 .

\section{Results}

miR-452 expression is down-regulated and has a negative correlation with BMI1 expression in human NSCLC tissues

By qRT-PCR, we detected the expression levels of miR-452 and BMI1 in NSCLC specimen and corresponding adjacent tissues $(n=60)$. Interestingly, the relatively lower expression of miR-452 and higher expression of BMI1 RNA were observed in tumor specimens compared with adjacent tissues (Fig. 1A and B). Moreover, miR-452 and BMI1 was confirmed to have an inverse correlation ( $r=-0.806, p<0.0001$; Fig. $1 C$ ). Subsequently, we divided all patients into two groups according to their miR-452 (or BMI1) expressions levels: those with less than median of miR-452 (or BMI1) expression levels and those with more than median of miR-452 (or BMI1) expression levels. Apparently, the median was used as a cutoff value. The detailed relationship between miR-452 or BMI1 expression and patients' clinicopathological characteristic was presented in Table 1 . Tumor stage (according to the $7^{\text {th }}$ TNM staging

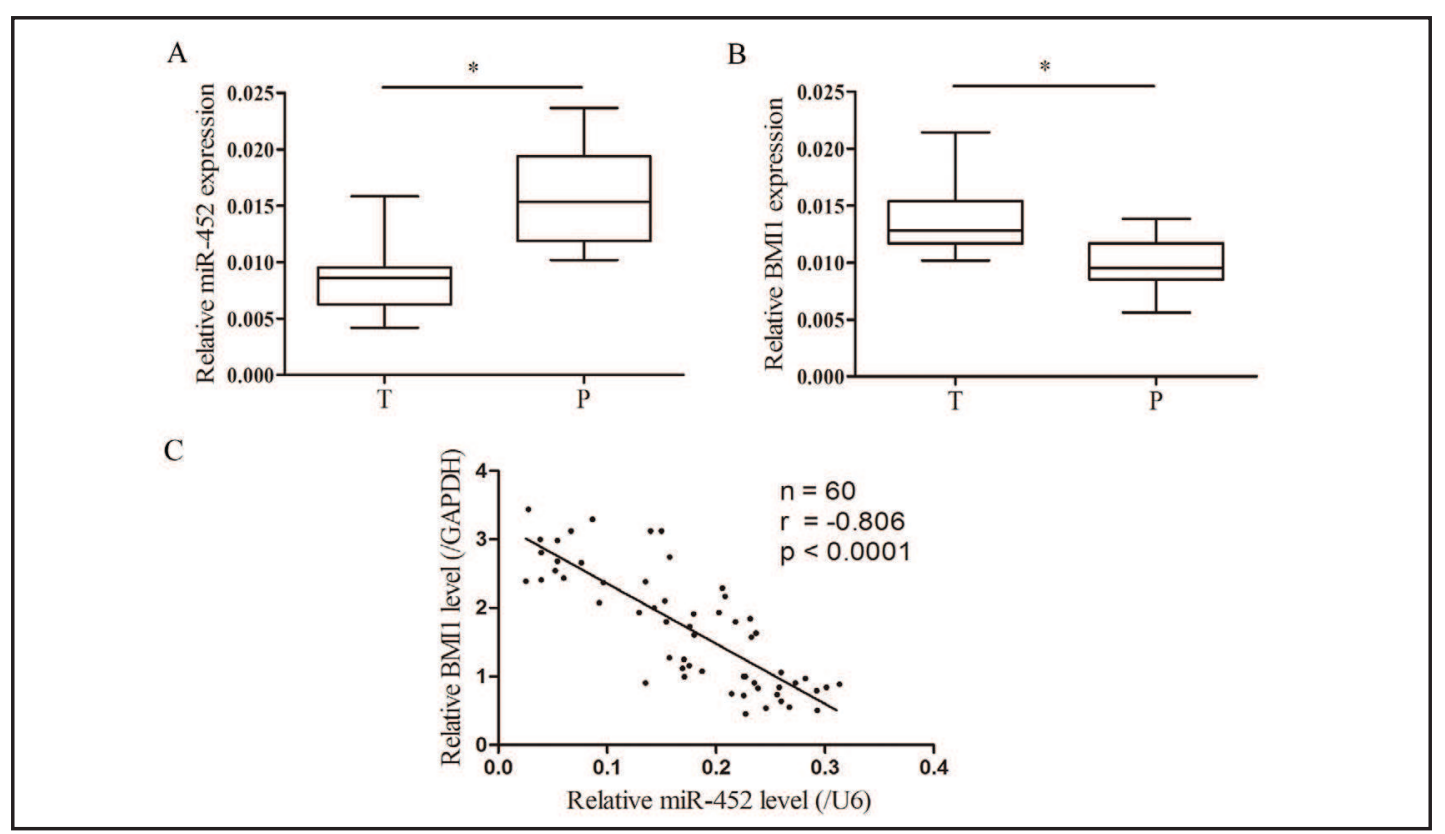

Fig. 1. Distinct expression patterns of miR-452 and BMI1 in NSCLC patients (n=60). (A) miR-452 mRNA expression level normalized by U6 in NSCLC tumor samples and corresponding adjacent tissues detected by using qRT-PCR. (B) BMI1 mRNA expression level normalized by GAPDH in NSCLC tumor samples and corresponding adjacent tissues also by using qRT-PCR. (C) A negative correlation observed between miR-452 and BMI1 mRNA expression levels. T and P referring to tumor samples and corresponding adjacent tissues, respectively. Data presented as mean \pm S.E.M. * indicating $\mathrm{p}<0.05$. 


\section{Cellular Physiology \\ Cell Physiol Biochem 2015;37:387-398 \\ \begin{tabular}{l|l}
\hline DOI: $10.1159 / 000430362$ & (c) 2015 S. Karger AG, Basel
\end{tabular} and Biochemistry Publisned online: August 27, $2015 \quad$ www.karger.com/cpb}

He et al.: Up-Regulation of miR-452 Inhibits Metastasis of NSCLC

Table 1. Expression levels of miR-452 in NSCLC and corresponding adjacent tissues. Median ${ }^{\mathrm{a}}=0.2907$; Me$\operatorname{dian}^{\mathrm{b}}=3.012$. AC: adenocarcinoma; SSC: suqamous cell carcinoma; ${ }^{*}$ indicates p value $<0.05$

\begin{tabular}{|c|c|c|c|c|c|c|c|}
\hline Characteristics & $\begin{array}{c}\text { All } \\
\text { Patients }\end{array}$ & $\begin{array}{l}\text { miR-452 low } \\
\text { Expression } \\
\left(\leq \text { Median }^{a}\right)\end{array}$ & $\begin{array}{l}\text { miR-452 high } \\
\text { Expression } \\
\text { (>Mediana) }\end{array}$ & $\begin{array}{c}\mathrm{p} \\
\text { value }\end{array}$ & $\begin{array}{l}\text { BMI-1 low } \\
\text { Expression } \\
\left(<\text { Median }^{\mathrm{b}}\right)\end{array}$ & $\begin{array}{l}\text { BMI-1 high } \\
\text { Expression } \\
\left(\geq \text { Median }^{\mathrm{b}} \text { ) }\right.\end{array}$ & $\begin{array}{c}\mathrm{p} \\
\text { value }\end{array}$ \\
\hline No. & 60 & 30 & 30 & & 30 & 30 & \\
\hline Age(years) & & & & 0.592 & & & 0.284 \\
\hline$<60$ & 38 & 20 & 18 & & 17 & 21 & \\
\hline$\geq 60$ & 22 & 10 & 12 & & 13 & 9 & \\
\hline Gender & & & & 0.791 & & & 0.184 \\
\hline Male & 23 & 11 & 12 & & 14 & 9 & \\
\hline Female & 37 & 19 & 18 & & 16 & 21 & \\
\hline Smoking index & & & & 0.781 & & & 0.405 \\
\hline$<400$ & 41 & 21 & 20 & & 22 & 19 & \\
\hline$\geq 400$ & 19 & 9 & 10 & & 8 & 11 & \\
\hline Histology & & & & 0.417 & & & \\
\hline AC & 39 & 18 & 21 & & 17 & 22 & 0.176 \\
\hline SSC & 21 & 12 & 9 & & 13 & 8 & \\
\hline $\begin{array}{l}\text { Operation } \\
\text { type }\end{array}$ & & & & 0.559 & & & 0.080 \\
\hline Lobectomy & 44 & 23 & 21 & & 19 & 25 & \\
\hline $\begin{array}{c}\text { Sub- } \\
\text { lobectomy }\end{array}$ & 16 & 7 & 9 & & 11 & 5 & \\
\hline Tumor stage & & & & $0.008^{*}$ & & & $0.035^{*}$ \\
\hline I/II & 36 & 13 & 23 & & 22 & 14 & \\
\hline III/IV & 24 & 17 & 7 & & 8 & 16 & \\
\hline Tumor size & & & & 0.284 & & & 0.592 \\
\hline $\mathrm{T} 1 / \mathrm{T} 2$ & 38 & 17 & 21 & & 20 & 18 & \\
\hline T3/T4 & 22 & 13 & 9 & & 10 & 12 & \\
\hline Metastasis & & & & $0.028^{*}$ & & & $0.006^{*}$ \\
\hline Yes & 40 & 24 & 16 & & 15 & 25 & \\
\hline No & 20 & 6 & 14 & & 15 & 5 & \\
\hline
\end{tabular}

system [14]) and the statue of lymph nodes metastases were verified to remarkably associate with miR-452 and BMI1 expression levels. Additionally, other parameters such as age, gender, smoking index, histology, and operation type, were not significantly associated with expression level of miR-452 or BMI1. These results were in accordance with the above correlation analysis, indicating a potential functional link of miR-452 and BMI1. Herein, we could initially draw a conclusion that miR-452 and BMI1 might participant in the invasion and metastasis of NSCLC.

miR-452 has no effect on cell proliferation and cell apoptosis in vitro

miR-452 was tested in four lung cancer cell lines (A549, SPCA1, H358, and H1299) and normal lung cell (16HBE). The expression levels of miR-452 in SPCA1 and A549 were exactly between those in H358 and H1299 (Fig. 2A). Based on the above expression pattern, we then choose SPCA1 and A549 cell lines to continue the function tests. Eventually, SPCA1 and A549 cell lines were transfected, and then divided into four groups: NC (mimics negative control), miR-452 mimics, inhibitor NC and miR-452 inhibitor. We conducted qRT-PCR to evaluate the transfection efficiency prior to the following investigations (Fig. 2B). To examine whether miR-452 could regulate NSCLC cell lines proliferation in vitro, we tested the effect of miR452 on proliferation by using CCK8 assay. The assay test suggested no distinct differences in proliferation between the above four groups in either A549 or SPCA1 cell lines at 24h, 48-h and 72-h time points (Fig. 2C). Furthermore, we also conducted apoptosis assay to investigate the effect of miR-452 on cell apoptosis. Similarly, the survival rate of cells transfected with miR-452 mimics was comparable with $\mathrm{NC}$, and the same trend was obtained 


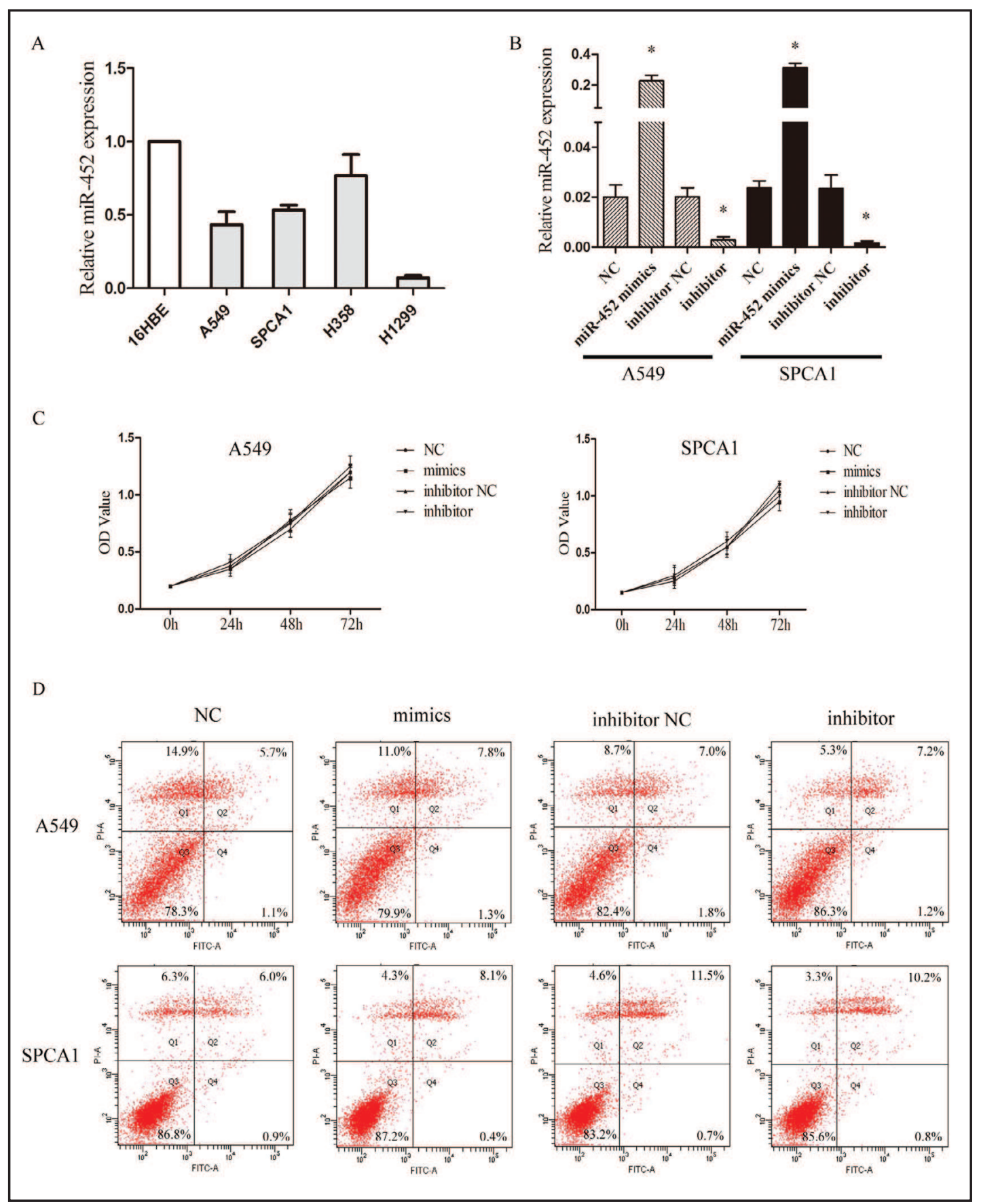

Fig. 2. No effect of miR-452 on cell proliferation and cell apoptosis in vitro (A) Distinct expression levels of miR-452 in four NSCLC cells lines (A549, SPCA1, H358, and H1299) and one normal cell line (16HBE). (B) Expression levels of miR-452 in A549 and SPCA1 cells transfected with control for miR-452 mimics (NC), miR-452 mimics, control for miR-452 inhibitor (inhibitor NC) and miR-452 inhibitor by using qRT-PCR. (C) CCK8 assay performed to assess cells proliferation. Absorbance at $450 \mathrm{~nm}$ presented with Mean \pm S.E.M. (D) Flow cytometry assay conducted to assess cells apoptosis in both A549 and SPCA1 cell lines. *suggesting significant difference while in comparison with control group $(\mathrm{p}<0.05)$.

in cells transfected with miR-452 inhibitor and those in inhibitor NC group (Fig. 2D). Taken together, miR-452 has no effect on cell proliferation and cell apoptosis in vitro. 


\section{Cellular Physiology Cell Physiol Biochem 2015;37:387-398 \\ \begin{tabular}{l|l}
$\overline{\text { DOI: 10.1159/000430362 }}$ & () 2015 S. Karger AG, Basel
\end{tabular}

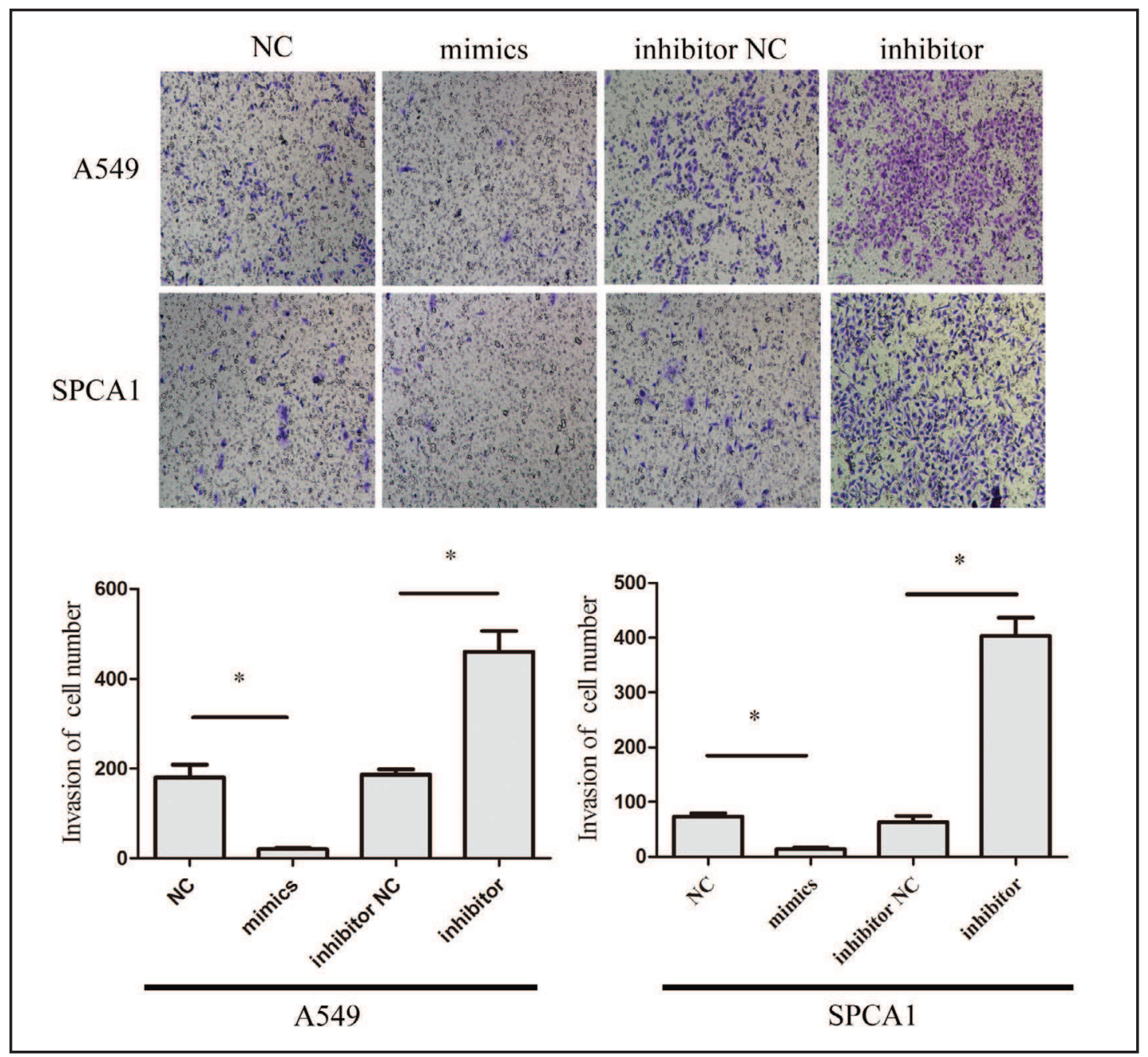

Fig. 3. miR-452 regulating the invasive capability of cell lines in vitro. A549 and SPCA1 treated with control for miR-452 mimics (NC), miR-452 mimics, control for miR-452 inhibitor (inhibitor NC) and miR-452 inhibitor, respectively. The transwell assay performed to assess the invasive capability of cells. The visualized images of invasive cells at the bottom of the membrane stained with crystal violet. Cell invasion capability quantified as cell numbers. All experiments performed three times and presented as Mean \pm S.E.M. * indicating $\mathrm{p}<0.05$.

Up-regulated miR-452 inhibits the invasive capability of NSCLC cells in vitro

Next, we explored the impact of miR-452 in cell invasion capacity using Transwell invasion assay. The Transwell invasion assay illustrated that overexpression of miR-452 inhibited cells lines invasion. Meanwhile, the reduced expression of miR-452 enhanced the invasion capability of both A549 and SPCA1 cell lines (Fig. 3). Collectively, it was obviously that miR-452 could inhibit the invasion capability of NSCLC cell lines in vitro.

miR-452 could binding the 3'-UTR of BMI1 and regulate its expression level

The bioinformatics method was used to predict the potential target gene of miR-452. These databases, mainly including miRWalk (http://www.umm.uni-heidelberg.de/apps/ $\mathrm{zmf} / \mathrm{mirwalk} /$ ), microRNA.org (http://www.microrna.org/microrna/getMirnaForm.do) and Target Scan (http://www.targetscan.org/), suggested that 3'-UTR (untranslated region) of BMI1 binds to miR-452 with a high score (mirSVR score: -1.0699). Thus, we hypothesized that 3 '-UTR fragment contained the predicted site, and then we cloned this site into pGL3 luciferase reporter vector (pGL3-BMI1) to uncover the correlation between miR-452 and 
A
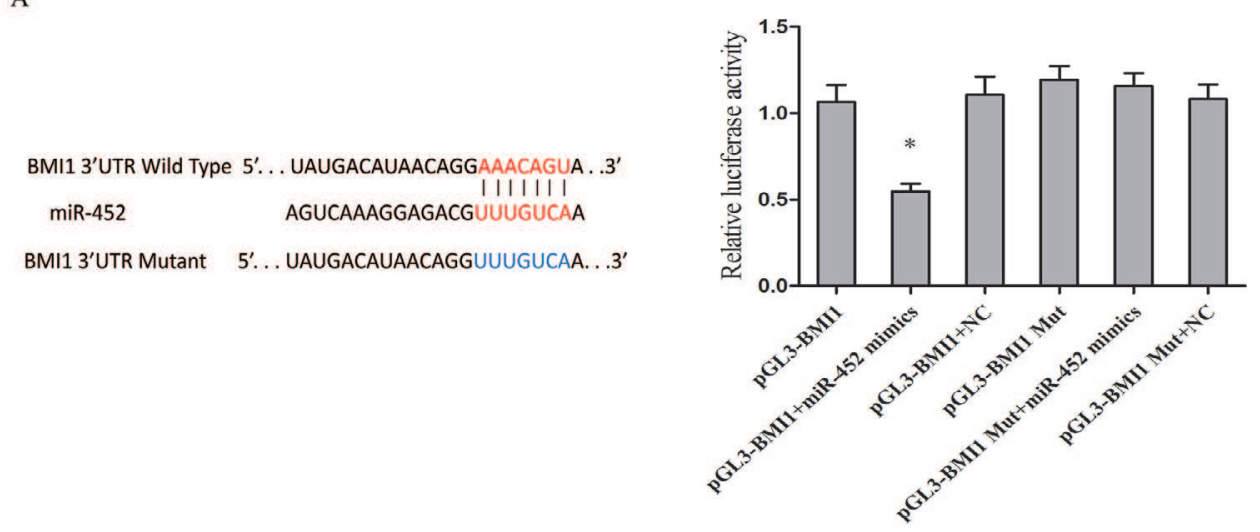

B
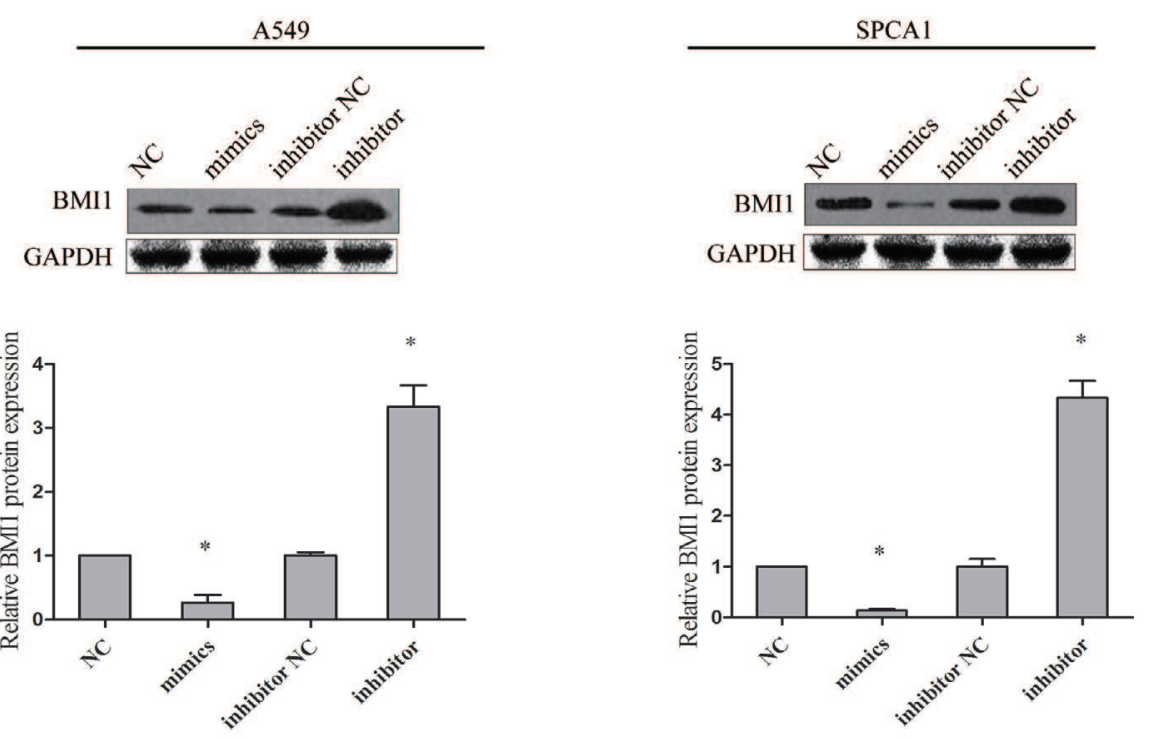

Fig. 4. miR-452 regulating BMI1 expression by binding its 3'-UTR. (A) The computationally predicted miR452 seed region at the 3'-UTR of BMI1 mRNA by using TargetScan database, cells co-transfected with miR452 mimics (or NC) and pGL3-BMI1 (or PGL3-BMI1-MUT) vector. Luciferase activity normalized by the ratio of firefly and Renilla luciferase signals. (B) BMI1 protein expression levels in both A549 and SPCA1 cells transfected with NC, miR-452 mimics, inhibitor NC and miR-452 inhibitor by using western-blot assay. GAPDH used as a control group. All experiments performed in triplicate and the band intensity value evaluated by Image J. Data presented as Mean \pm S.E.M. * indicating $\mathrm{p}<0.05$.

BMI1 expression. Meanwhile, we set the control group as the $3^{\prime}$-UTR fragment with mutant sequence in the predicted target site (pGL3-BMI1-MUT). Interestingly, the luciferase activity significantly decreased in A549 cells transfected with miR-452 mimics and pGL3-BMI 1 vectors. Nevertheless, miR-452 mimics had no effect on luciferase activity when target cells were transfected with pGL3-BMI1-MUT vector (Fig. 4A). Furthermore, western blot assays were performed to determine the expression of BMI 1 while the miR-452 expression level was changed in vitro. The result showed that miR-452 had a negative regulatory effect on BMI1 expression in both A549 and SPCA1 cell lines. In other words, reduced expression of miR452 could up-regulate BMI 1 expression and increased expression of miR-452 accordingly down-regulate BMI1 expression (Fig. 4B). These data agreed with our previous hypothesis that BMI1 was one of the target genes of miR-452, and it could regulate BMI1 expression by binding its 3'-UTR in NSCLC cell lines. 
A
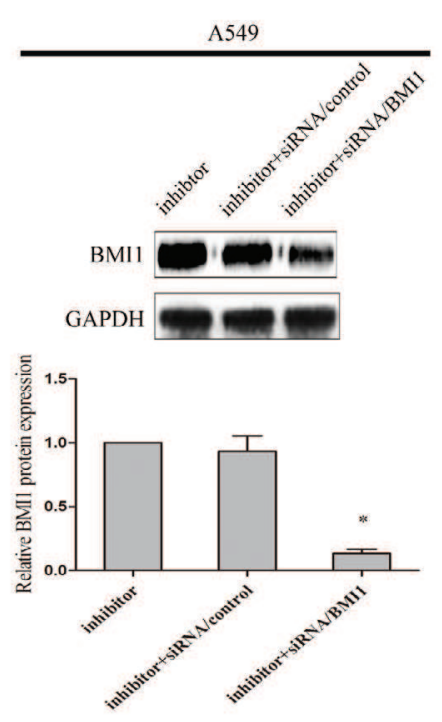

$\mathrm{B}$
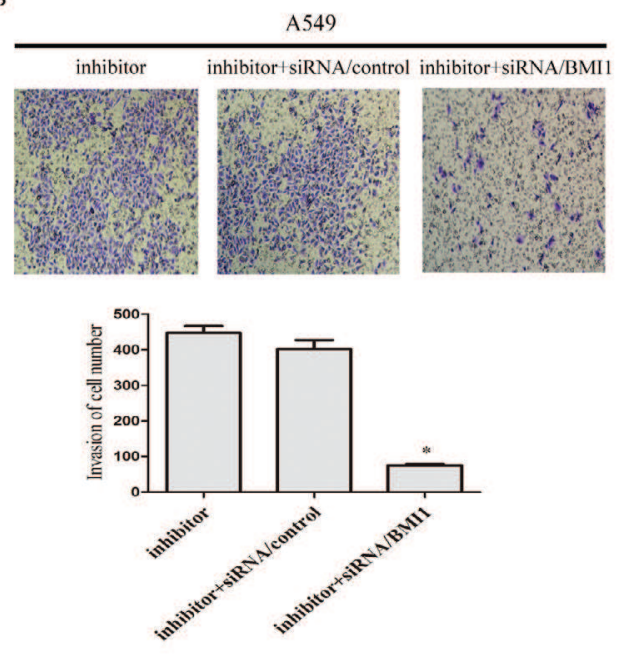
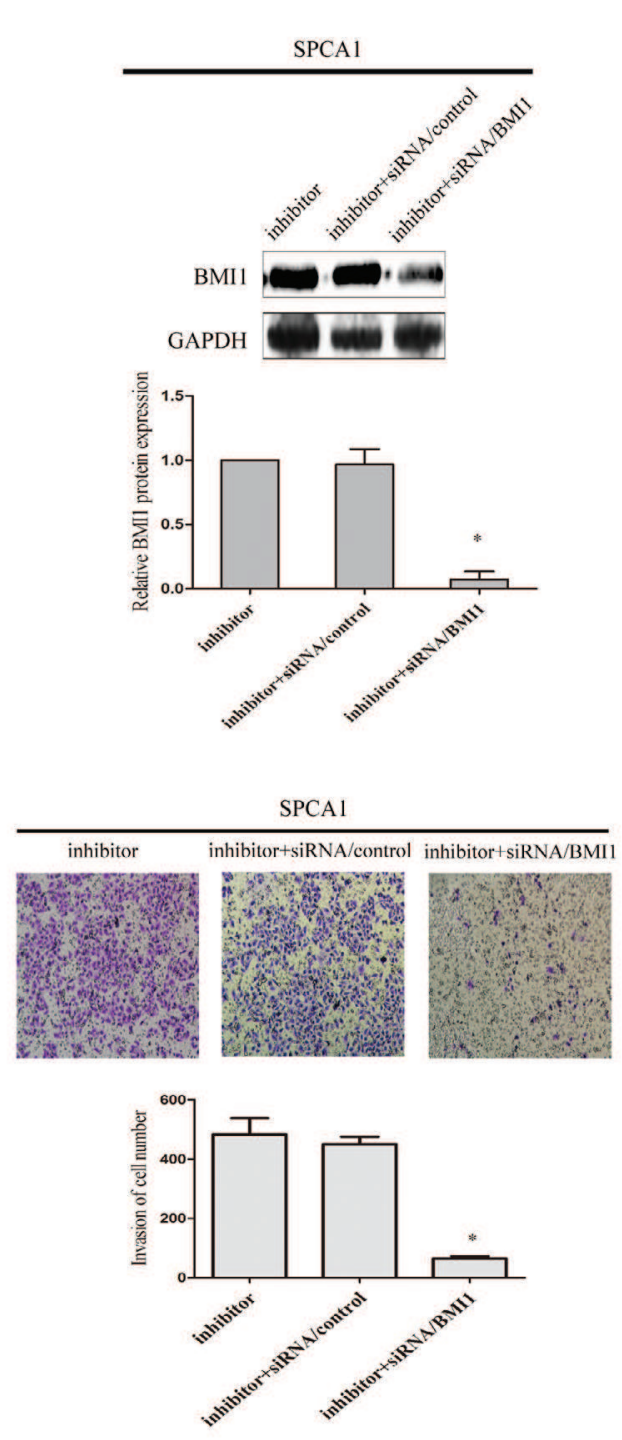

Fig. 5. Expression of BMI1 eliminating the enhanced invasion capability of cells induced by down-regulated miR-452. (A) Western blot assay used to test the transfection efficiency, expression of BMI1 normalized to GAPDH. Both A549 and SPCA1 cell lines co-transfected with miR-452 inhibitor and siRNA/BMI1, control groups referring to cells transfected with miR-452 inhibitor and those co-transfected with miR-452 inhibitor and siRNA/control. (B) Transwell assay used to assess the invasive capability of cells. The visualized images of invasive cells at the bottom of the membrane stained with crystal violet. Cell invasion capability quantified as cell numbers. All experiments performed three times and presented as Mean \pm S.E.M. * indicating $\mathrm{p}<0.05$.

Silencing of BMI1 by siRNA could reverse the enhanced capability of cell invasion induced by down-regulated miR-452

To explore whether the functional effect of miR-452 on NSCLC cells was associated with BMI1. As shown above, the expression level of BMI1 was increased in both A549 and SPCA1 cell lines transfected with miR-452 inhibitor. In view of this, RNA interference (siRNA) was used to silence the expression of BMI1. We co-transfected both miR-452 inhibitor and siRNA/BMI1 in both A549 and SPCA1 cell lines. Meanwhile, cell lines co-transfected with miR-452 inhibitor and siRNA/control were regarded as the control groups. Finally, we performed western-blot assays to test the transfection efficiency. In comparison with the 


\section{Cellular Physiology Cell Physiol Biochem 2015;37:387-398 \\ \begin{tabular}{c|c|c|c|}
\hline DOI: 10.1159/000430362 & (c) 2015 S. Karger AG, Basel
\end{tabular} \\ \begin{tabular}{l|l} 
and Biochemistry Publisned oninne: August 27, 2015 & www.karger.com/cpb
\end{tabular} \\ He et al.: Up-Regulation of miR-452 Inhibits Metastasis of NSCLC}

control group, the expression of BMI1 was remarkably reduced in both A549 and SPCA1 cells co-transfected with miR-452 inhibitor and siRNA/BMI1 (Fig. 5A). As shown in Fig. $5 \mathrm{~B}$, transwell invasion assay was subsequently conducted, which suggested that silencing of BMI1 by siRNA partially reverse the enhanced capability of invasion induced by downregulated miR-452.

\section{Discussion}

Our previous studies have illustrated that invasion and metastasis are key factors influencing the rate of long-term survival of NSCLC $[15,16]$. Even diagnosed at early stage and surgically resected successfully, a considerable number of NSCLC patients will suffer from metastasis or recurrence. Hence, urgently clarifying the mechanisms of invasion and metastasis of malignant cells will definitely bring benefits to those NSCLC patients. In the past decades, many investigators focused on the connection of genes and proteins participating in the development of lung cancer. However, since Johnson firstly reported the involvement of miRNAs in lung cancer in 2005, an increasing number of miRNAs were identified to play a crucial role in progression and metastasis in NSCLC. Thus they probably provide us with an alternative strategy for uncovering the underlying mechanism of the invasion and metastasis of NSCLC cells.

miRNAs, as regulators of gene expression, play fundamental roles in many physical processes such us proliferation, apoptosis and invasion [17, 18]. So far, Mounting literatures have documented the functions of lung cancer-related miRNAs. For instance, Gu and his co-workers verified that miR-150 induced cell proliferation inhabitation and apoptosis in NSCLC by targeting BAK1 [19]. Meanwhile, our previous work has also confirmed that miR-204 and miR-30c function as regulators in the progression of NSCLC by targeting specific genes [15, 16]. Recently, miR-452 was regarded as tumor suppressor in glioma [7], prostate[20] and breast malignancies[8], which was supported by our findings that miR452 expression was significantly reduced in tumor comparing with corresponding adjacent tissues and was negatively correlated with the tumor stage and lymph nodes metastases. Here, aberrant expression of miR-452 clearly played an important role in cells invasion capability and also influenced cells apoptosis rather than cells proliferation. Controversially, it was also confirmed as oncogene in esophageal cancer [6], urothelial carcinoma [21] and hepatocellular carcinoma [22]. The heterogeneity of miR-452 biological activities in diverse malignancies was probably attributed to the distinct context of various micro-environments [7]. In addition, limited study has documented the target gene of miR-452. Only Zheng et al. reported that miR- 452 promoted tumorigenesis in hepatocellular carcinoma by targeting cyclin-dependent kinase inhibitor 1B [22]. In our study, the expression levels of miR-452 and BMI1 were tested negatively correlated within limited samples of NSCLC. This encouraged us to elucidate the potential link between miR-452 and BMI1 in NSCLC.

BMI1 gene, a member of the Polycomb group genes (PcG), was first identified as an oncogene that interacted with c-Myc in the development of murine lymphoma [23]. Currently, it was reported that BMI1 is associated with the metastasis of many cancers. Overexpression of BMI1 was positively correlated with lymphatic metastasis in breast cancers [24]. Li and his colleagues documented that BMI1 was associated with increased risk of local recurrence and metastasis, thus predicting poor outcomes in colon cancers [25]. Additionally, Meng et al. showed that BMI1was obviously correlated with clinical stage and metastasis and probably contributed to metastasis of lung adenocarcinoma [26]. Our observation was in line with the above investigations. Here, we discovered that BMI1 was up-regulated in NSCLC tumor tissues and was positively associated with tumor stage, size and metastasis. Interestingly, we also found that silence of BMI1 by siRNA could eliminate the enhanced cells invasion capability induced by reduced expression of miR-452.

In conclusion, our investigations illustrated that down-regulation of miR-452, accompanied by up-regulation of BMI1, was detected in NSCLC tumor samples comparing 


\section{Cellular Physiology Cell Physiol Biochem 2015;37:387-398 \begin{tabular}{c|c}
\hline DOI: 10.1159/000430362 & (c) 2015 S. Karger AG, Basel
\end{tabular} \begin{tabular}{l|l} 
and Biochemistry Publisned oninne: August 27, 2015 & www.karger.com/cpb \\
\hline
\end{tabular}}

with corresponding adjacent tissues. Both of them were correlated with the tumors stage and lymph nodes metastasis. In vitro, aberrant miR-452 expression could regulate invasion capability of cells lines by binding BMI1 3'-UTR. Furthermore, we also confirmed that enhanced capability of cell invasion induced by down-regulation of miR-452 could be reversed by repression of BMI1. Further explorations involving miR-452-BMI1 pathway may bring new therapeutic strategy to the development of NSCLC.

\section{Abbreviations}

NSCLC (non-small cell lung cancer); 3'-UTR (3'-untranslated regions); qRT-PCR (Quantitative Real Time- Polymerase Chain Reaction); FBS (fetal calf serum); EDTA (ethylene Diamine Tetraacetic Acid); CCK-8 (cell-counting Kit-8).

\section{Disclosure Statement}

None.

\section{References}

1 Torre LA, Bray F, Siegel RL, Ferlay J, Lortet-Tieulent J, Jemal A: Global cancer statistics, 2012. CA Cancer J Clin 2015;65:87-108.

2 Chen W, Zheng R, Zhang S, Zhao P, Zeng H, Zou X: Report of cancer incidence and mortality in china, 2010. Ann Transl Med 2014;2:61.

-3 Siegel R, Ma J, Zou Z, Jemal A: Cancer statistics, 2014. CA Cancer J Clin 2014;64:9-29.

4 Furak J, Trojan I, Szoke T, Agocs L, Csekeo A, Kas J, Svastics E, Eller J, Tiszlavicz L: Lung cancer and its operable brain metastasis: Survival rate and staging problems. Ann Thorac Surg. 2005;79:241-247; discussion 241-247.

5 Yang WB, Chen PH, Hsu Ts, Fu TF, Su WC, Liaw H, Chang WC, Hung JJ: Sp1-mediated microrna-182 expression regulates lung cancer progression. Oncotarget 2014;5:740-753.

6 Liu SG, Qin XG, Zhao BS, Qi B, Yao WJ, Wang TY, Li HC, Wu XN: Differential expression of mirnas in esophageal cancer tissue. Oncol Lett 2013;5:1639-1642.

7 Liu L, Chen K, Wu J, Shi L, Hu B, Cheng S, Li M, Song L: Downregulation of mir-452 promotes stem-like traits and tumorigenicity of gliomas. Clin Cancer Res 2013;19:3429-3438.

8 van Schooneveld E, Wouters MC, Van der Auwera I, Peeters DJ, Wildiers H, Van Dam PA, Vergote I, Vermeulen PB, Dirix LY, Van Laere SJ: Expression profiling of cancerous and normal breast tissues identifies micrornas that are differentially expressed in serum from patients with (metastatic) breast cancer and healthy volunteers. Breast Cancer Res 2012;14:R34.

-9 Liu C, Kelnar K, Vlassov AV, Brown D, Wang J, Tang DG: Distinct microrna expression profiles in prostate cancer stem/progenitor cells and tumor-suppressive functions of let-7. Cancer Res 2012;72:3393-3404.

-10 Zhang X, Yang X, Zhang Y, Liu X, Zheng G, Yang Y, Wang L, Du L, Wang C: Direct serum assay for cell-free bmi-1 mrna and its potential diagnostic and prognostic value for colorectal cancer. Clin Cancer Res 2015;21:1225-1233.

11 Jin M, Zhang T, Liu C, Badeaux MA, Liu B, Liu R, Jeter C, Chen X, Vlassov AV, Tang DG: Mirna-128 suppresses prostate cancer by inhibiting bmi-1 to inhibit tumor-initiating cells. Cancer Res 2014;74:4183-4195.

$\checkmark 12$ Becker M, Korn C, Sienerth AR, Voswinckel R, Luetkenhaus K, Ceteci F, Rapp UR: Polycomb group protein bmi1 is required for growth of raf driven non-small-cell lung cancer. PLoS One 2009;4:e4230.

13 Jiang L, Li J, Song L: Bmi-1, stem cells and cancer. Acta Biochim Biophys Sin (Shanghai) 2009;41:527-534.

14 Detterbeck FC, Boffa DJ, Tanoue LT: The new lung cancer staging system. Chest 2009;136:260-271.

15 Xia Y, Chen Q, Zhong Z, Xu C, Wu C, Liu B, Chen Y: Down-regulation of mir-30c promotes the invasion of non-small cell lung cancer by targeting mta1. Cell Physiol Biochem 2013;32:476-485. 


\section{Cellular Physiology Cell Physiol Biochem 2015;37:387-398 \begin{tabular}{ll|l} 
and Biochemistry & $\begin{array}{l}\text { DOI: 10.1159/000430362 } \\
\text { Published oninne: August 27, } 2015\end{array}$ & $\begin{array}{l}\text { (c) 2015 S. Karger AG, Basel } \\
\text { www.karger.com/cpb }\end{array}$ \\
\hline
\end{tabular}}

He et al.: Up-Regulation of miR-452 Inhibits Metastasis of NSCLC

16 Xia Y, Zhu Y, Ma T, Pan C, Wang J, He Z, Li Z, Qi X, Chen Y: Mir-204 functions as a tumor suppressor by regulating six1 in nsclc. FEBS Lett 2014;588:3703-3712.

-17 Yan GJ, Yu F, Wang B, Zhou HJ, Ge QY, Su J, Hu YL, Sun HX, Ding LJ: Microrna mir-302 inhibits the tumorigenicity of endometrial cancer cells by suppression of cyclin d1 and cdk1. Cancer Lett 2014;345:3947.

18 Yongchun Z, Linwei T, Xicai W, Lianhua Y, Guangqiang Z, Ming Y, Guanjian L, Yujie L, Yunchao H: Microrna-195 inhibits non-small cell lung cancer cell proliferation, migration and invasion by targeting myb. Cancer Lett 2014;347:65-74.

19 Gu XY, Wang J, Luo YZ, Du Q, Li RR, Shi H, Yu TP: Down-regulation of mir-150 induces cell proliferation inhibition and apoptosis in non-small-cell lung cancer by targeting bak1 in vitro. Tumour Biol 2014;35:5287-5293.

20 Kristensen H, Haldrup C, Strand S, Mundbjerg K, Mortensen MM, Thorsen K, Ostenfeld MS, Wild PJ, Arsov C, Goering W, Visakorpi T, Egevad L, Lindberg J, Gronberg H, Hoyer S, Borre M, Orntoft TF, Sorensen KD: Hypermethylation of the gabre $\sim$ mir-452 mir-224 promoter in prostate cancer predicts biochemical recurrence after radical prostatectomy. Clin Cancer Res 2014;20:2169-2181.

-21 Veerla S, Lindgren D, Kvist A, Frigyesi A, Staaf J, Persson H, Liedberg F, Chebil G, Gudjonsson S, Borg A, Mansson W, Rovira C, Hoglund M: Mirna expression in urothelial carcinomas: Important roles of mir-10a, mir-222, mir-125b, mir-7 and mir-452 for tumor stage and metastasis, and frequent homozygous losses of mir-31. Int J Cancer 2009;124:2236-2242.

-22 Zheng Q, Sheng Q Jiang C, Shu J, Chen J, Nie Z, Lv Z, Zhang Y: Microrna-452 promotes tumorigenesis in hepatocellular carcinoma by targeting cyclin-dependent kinase inhibitor $1 \mathrm{~b}$. Mol Cell Biochem 2014;389:187-195.

-23 van Lohuizen M, Verbeek S, Scheijen B, Wientjens E, van der Gulden H, Berns A: Identification of cooperating oncogenes in e mu-myc transgenic mice by provirus tagging. Cell 1991;65:737-752.

-24 Kim JH, Yoon SY, Jeong SH, Kim SY, Moon SK, Joo JH, Lee Y, Choe IS, Kim JW: Overexpression of bmi-1 oncoprotein correlates with axillary lymph node metastases in invasive ductal breast cancer. Breast (Edinburgh, Scotland) 2004;13:383-388.

25 Li DW, Tang HM, Fan JW, Yan DW, Zhou CZ, Li SX, Wang XL, Peng ZH: Expression level of bmi-1 oncoprotein is associated with progression and prognosis in colon cancer. J Cancer Res Clin Oncol 2010;136:997-1006.

-26 Meng X, Wang Y, Zheng X, Liu C, Su B, Nie H, Zhao B, Zhao X, Yang H: Shrna-mediated knockdown of bmi-1 inhibit lung adenocarcinoma cell migration and metastasis. Lung Cancer 2012;77:24-30. 